\title{
Consumo de frutas y verduras en adultos mayores relación con características socio demográficas
}

\author{
Ivonne Bernui, Juana Flores, Diego Saavedra \\ Centro de Investigación en Bioquímica y Nutrición y Departamento de Nutrición, Facultad de Medicina, UNMSM
}

Objetivos: Relacionar el consumo de frutas y verduras con las características de sexo, edad, condición socio-económica y nivel educativo de los adultos mayores.

Diseño: Estudio descriptivo, correlacional.

Institución: Centro de Investigación en Bioquímica y Nutrición y Departamento de Nutrición, Facultad de Medicina, UNMSM.

Participantes: Adultos mayores no institucionalizados, autovalentes, de dos clubes de adultos mayores en Pueblo Libre y Chaclacayo.

Intervenciones: Se aplicó una encuesta sobre características socio-económicas y frecuencia de consumo de alimentos. Previamente se aplicó el test de Folstein, modificado por Icaza, para evaluar su memoria.

Principales medidas de resultados: Promedio de raciones de frutas y verduras por día.

Resultados: Se encuestó 48 adultos mayores, cuya edad promedio fue 73,4 6,6,6 (60 a 86 años); 75\% fueron mujeres. La mitad estaba casada y vivía con hijos y nietos. Veintiún encuestadas pertenecían al nivel socioeconómico (NSE) bajo y 27 al NSE medio. El promedio general del consumo de frutas, verduras y frutas más verduras fue de: 2,4 $\pm 1,2 ; 2,1 \pm 0,9$

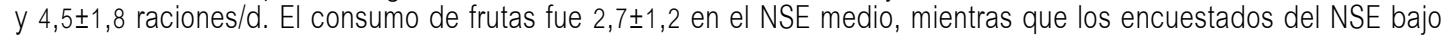
consumieron 1,9 $\pm 1,2(p<0,05)$. Quienes cumplieron con ingerir 5 raciones/dia de frutas y verduras tuvieron en promedio mayor edad $(76,2 \pm 5,2)$ que los que no consumieron dicha cantidad $(72,1 \pm 6,9)$. Uno de cada tres participantes cumplió con ingerir 5 raciones de frutas y verduras al día.

Conclusiones: El consumo de frutas y verduras fue bajo. Mientras el consumo de frutas estuvo relacionado por el NSE, el consumo de frutas y verduras estuvo relacionado con la edad.

Palabras clave: Consumo de frutas, consumo de verdura, adultos mayores.

\section{Responsabilidad médica presunta. Clínica Forense 2012}

\author{
Shérmany Aronés, Rosa Carrera, Delforth Laguerre, Rafael Cano, Mary Lapiz, Rosario Lira
}

Instituto de Medicina Legal, Ministerio Público, e Instituto de Patología, UNMSM

Introducción: La responsabilidad profesional médica presunta, por denuncias en personas, con sospecha de error médico, requiere de calificación pericial especializada.

Objetivos: Establecer la incidencia de la responsabilidad profesional médica presunta, por denuncias en personas, con sospecha de error médico en la clínica forense.

Diseño: Cuantitativo, observacional, transversal.

Institución: Instituto Medicina Legal, Ministerio Público, e Instituto de Patología, UNMSM.

Material de estudio: Informes periciales de reconocimientos medico legales en historias clínicas.

Intervenciones: Médico legales por denuncia jurisdiccional, por sospecha de responsabilidad.

Principales medidas de resultados: Medidas de tendencia central porcentual.

Resultados: Se analizó 142 expedientes, de enero a junio de 2012, encontrando sexo femenino 61,3\% (87), masculino $38,7 \%$ (55), menores de edad 10,6\% (15), 18 a 50 años 23,9\% (34), >51 años 65,5\% (93), con incremento en enero, abril.

Conclusiones: El incremento de denuncias se incrementó con la edad y la mayor incidencia correspondió a aquellos pacientes mayores de 60 años, que están comprendidos en la tercera edad y requieren una atención especial y de cuidado.

Palabras clave: Responsabilidad médica, error médico. 